\title{
Family structure as a predictor of screen time among youth
}

Rachel McMillan, Michael A Mclsaac, Ian Janssen

The family plays a central role in the development of health-related behaviors among youth. The objective of this study was to determine whether non-traditional parental structure and shared custody arrangements predict how much time youth spend watching television, using a computer recreationally, and playing video games. Participants were a nationally representative sample of Canadian youth $(\mathrm{N}=26,068)$ in grades $6-10$ who participated in the 2009/10 Health Behaviour in School-aged Children Survey. Screen time in youth from single parent and reconstituted families, with or without regular visitation with their non-residential parent, was compared to that of youth from traditional dualparent families. Multiple imputation was used to account for missing data. After multiple imputation, the relative odds of being in the highest television, computer use, video game, and total screen time quartiles were not different in boys and girls from non-traditional families by comparison to boys and girls from traditional dual-parent families. In conclusion, parental structure and child custody arrangements did not have a meaningful impact on screen time among youth. 
2 TITLE: Family structure as a predictor of screen time among youth

4 ABSTRACT: The family plays a central role in the development of health-related behaviors among 5 youth. The objective of this study was to determine whether non-traditional parental structure and

6 shared custody arrangements predict how much time youth spend watching television, using a

7 computer recreationally, and playing video games. Participants were a nationally representative sample

8 of Canadian youth ( $\mathrm{N}=26$ 068) in grades 6-10 who participated in the 2009/10 Health Behaviour in

9 School-aged Children Survey. Screen time in youth from single parent and reconstituted families, with

10 or without regular visitation with their non-residential parent, was compared to that of youth from

11 traditional dual-parent families. Multiple imputation was used to account for missing data. After

12 multiple imputation, the relative odds of being in the highest television, computer use, video game, and

13 total screen time quartiles were not different in boys and girls from non-traditional families by

14 comparison to boys and girls from traditional dual-parent families. In conclusion, parental structure and

15 child custody arrangements did not have a meaningful impact on screen time among youth.

17 AUTHORS: Rachel McMillan ${ }^{1}$, Michael McIsaac ${ }^{1}$, and Ian Janssen ${ }^{1,2}$

19 AUTHOR AFFILIATIONS: ${ }^{1}$ Department of Public Health Sciences, Queen's University, Kingston,

20 Ontario, Canada. ${ }^{2}$ School of Kinesiology and Health Studies, Queen's University, Kingston, Ontario,

21 Canada

22

23 ADDRESS FOR CORRESPONDENCE: Professor Ian Janssen, School of Kinesiology and Health

24 Studies, Queen's University, Kingston, Ontario, Canada K7L 3N6. Phone: (613) 533-6000 ext. 78631.

25 Email: ian.janssen@queensu.ca 


\section{INTRODUCTION}

Sedentary activities, including screen time behaviors such as watching television, using a computer and playing video games, have become ubiquitous in the lives of most young people. In Canada, fewer than 1 in 5 youth aged 10-16 meet the public health recommendation to limit their total recreational screen time to 2 hours or less per day (Freeman et al., 2012). This is concerning given the findings of a recent systematic review which concluded that excessive screen time in youth is independently associated with several physical, mental, and social health problems such as obesity, the metabolic syndrome, decreased academic achievement, and engagement in antisocial behaviors (Tremblay et al., 2011b). Understanding the determinants of youths' screen time is therefore a public health priority.

One such determinant of youth screen time may be family structure, which is also associated with a wide range of behavioral, developmental, and health-related outcomes (Bramlett and Blumberg, 2007; Jablonska and Lindberg, 2007). Single parent families and reconstituted families (i.e. families headed by a parent and their partner) are more likely to be of low socioeconomic status than traditional families (Thomson and McLanahan, 2012). Furthermore, single parents may face time constraints that limit their ability to monitor or co-participate in their children's health-related behaviors (Quarmby et al., 2011). Approximately one in three Canadian youth have a non-traditional family structure (Freeman et al., 2012).

Quantitative studies examining the association between family structure and screen time have produced inconsistent results. Some studies report that youth from non-traditional families accumulate more screen time (Lindquist et al., 1999; Gorley et al., 2004; Quarmby and Dagkas, 2010), while others show that the relationship holds only for girls (Bagley et al., 2006; Hesketh et al., 2006; Sisson and Broyles, 2012) or boys (Gorely et al., 2009) and still other studies show null results (Salmon et al., 2005; Hardy et al., 2006). A major limitation of these studies is that they did not consider the diversity 
51 of modern families. The majority defined parental family structure as simply single- or dual-parent,

52 therefore overlooking potential differences between traditional dual-parent families and reconstituted

53 dual-parent families that include a stepparent or parent's partner (Thomson and McLanahan, 2012). No

54 studies have looked at how shared custody arrangements, which may involve the youth visiting or

55 living with a non-residential parent, affect screen time. This is of interest given that spending time with

56 a non-residential parent may negate some of the negative health outcomes related to being from a

57 single parent family (Bauserman, 2002; Jablonska and Lindberg, 2007; Bjarnason et al., 2012).

The purpose of this study was to examine whether family structure, determined based on the number of adults in the home and their relationship to the young person, is associated with screen time.

60 This study also considered whether regular contact with a non-residential parent influenced this

61 relationship. Ultimately, it is hoped that this research will contribute to our understanding of how

62 excessive screen time behaviors develop and assist in identifying high-risk youth for targeted

63 interventions.

\section{MATERIALS AND METHODS}

\section{Study design and population}

Study data are based on the nationally representative cross-sectional 2009/2010 Canadian

68 Health Behaviour in School-aged Children Survey (HBSC). The HBSC is conducted every 4 years in

6943 countries in collaboration with the World Health Organization (Currie et al., 2009; Freeman et al.,

70 2012). This study is limited to the Canadian data. The HBSC consists of a standardized self-report

71 survey filled out in a classroom setting, with the goal of determining the prevalence and distribution of

72 a wide range of psychological, social and physical determinants of health in adolescents. All items in

73 the HBSC study are continuously developed, piloted, and validated by the HBSC international network

74 (Currie et al., 2009; Freeman et al., 2012). 
Ethics approval for the 2009/2010 Canadian HBSC was given from Health Canada and the

76 General Research Ethics Board at Queen's University. Depending on the jurisdictional requirements at

77 the participating schools, informed consent from the parents/guardians of participating students could

78 have been obtained in an active or passive manner. In both situations a letter of information was sent

79 home to parents/guardians. If active consent was required, the parent/guardian had to sign the letter

80 and it had to be returned to the school or the student was not allowed to participate. If passive consent

81 was required, the parent did not have to sign or return the letter if they allowed their child to

82 participate. Conversely, they were asked to sign and return the letter if they did not want their child to

83 participate. Irrespective of whether active or passive consent was used, student participants had to

84 provide their informed consent, which was demonstrated by their willingness to complete the survey.

The 2009/2010 Canadian HBSC had a 77\% response rate. The final sample consisted of 26,068

86

87

students in grades 6-10 (approximate ages 11-15 years) from 436 public schools across Canada. All provinces and territories participated, with the exceptions of New Brunswick and Prince Edward Island. The provincial samples were obtained using a two-tiered cluster-sampling procedure to sample entire classrooms for participation; all students living in the three territories were invited to participate if they met the study inclusion criteria to ensure adequate representation. Students attending private, on-reserve, special needs or home-based schools were excluded, as were those who were absent from school on the day of the survey.

\section{Exposure (family structure)}

Information on family structure was derived from two questions on the HBSC. The first asked participants to check off the adults who live in the home "where [they] live all or most of the time" from a list of choices including mother, father, stepmother (or father's girlfriend) and stepfather (or mother's boyfriend). The second asked participants to indicate whether they had a second home and, if they did, to identify how often they stayed there ("half the time", "regularly but less than half the 
99 time", "sometimes" or "hardly ever"). Families were defined as traditional (includes both a mother and

100 a father), single parent (includes either a mother or a father), or reconstituted (includes either a mother

101 or a father and either a stepmother/father's girlfriend or stepfather/mother's boyfriend). Adolescents

102 from non-traditional families were further defined as having "regular visitation" with a second parent if

103 they had a second home and reported visiting it "half the time" or "regularly but less than half the

104 time" and "irregular visitation" if the adolescent reported not having a second home, or having a second

105 home but visiting it "sometimes" or "hardly ever". Youths who reported that neither their mother nor

106 their father lived in their primary home constituted $\sim 4 \%$ of the sample and were excluded from the

107 analysis.

108 Outcome (screen time)

109 Information on the three screen time behaviors of interest was obtained by asking participants to 110 report how many hours in their free time on a typical weekday and weekend day they usually "watch 111 television (including videos and DVDs)", "play games on a computer or games console (Playstation, 112 Xbox, Gamecube, etc)" or "use a computer for chatting on-line, internet, emailing, homework, etc".

113 For each question there were 9 ordinal response options, ranging from "none at all" to "about 7 or more

114 hours a day". A weighted average of weekly time spent in each screen time behavior was calculated.

115 A validation study of a similar questionnaire measuring weekly television use in adolescents showed

116 that participants' responses were significantly correlated $(\mathrm{r}=0.47)$ with television viewing time as

117 measured using a detailed 7-day log (Schmitz et al., 2004). Screen time was dichotomized so that those

118 in the highest quartile of weekly time spent in each screen time behavior could be compared to those in

119 the lower three quartiles. Separate analyses were performed comparing those who spent $>2$ hours in

120 each screen time behavior to those who spent $\leq 2$ hours, as screen time guidelines have recommended

121 this threshold (American Academy of Pediatrics, 2001; Tremblay et al., 2011a).

\section{Covariates}


Potential covariates for the model of the relationship between family structure and screen time

124 were selected based on previous literature and their availability within the HBSC. These included

125 gender, grade, ethnicity (Canadian, which includes those who self-identify as both Caucasian and

126 Aboriginal ethnicity, East and Southeast Asian, South Asian, Black, Arab, or other, which includes

127 those of mixed ethnicity and who also who self-identify as other), immigration status (non-

128 immigrant/immigrated $>5$ years ago or immigrated $\leq 5$ years ago), presence of siblings (yes or no), and

129 family affluence. Family affluence was measured through a self-report item on the HBSC that asked

130 students to report "how well off [they] think [their] family is", with five ordinal responses ranging from

131 "not at all well off" to "very well off". The top and bottom two responses were combined to create a

132 three-level ordinal measure of perceived family affluence.

\section{Statistical analysis}

All analyses used survey procedures in SAS 9.4 to account for the complex sampling design used by the HBSC, including clustering at the classroom and provincial levels and sampling weights.

136 All analyses were stratified by gender. The HBSC sample population was characterized using simple

137 descriptive statistics. Cross-tabulations of the average amount of time spent in each screen time

138 behavior by family structure were calculated, and differences between family structures were assessed

139 using analysis of covariance after adjusting for relevant confounders. A Bonferroni correction was

140 used to account for 10 multiple group comparisons. Note that the $95 \%$ confidence intervals (CI) for the

141 group means that are presented in the manuscript were not adjusted to account for multiple group

142 comparisons; we only corrected the P values used to denote statistical group differences.

Multiple logistic regression was used to further quantify associations between family structure

144 and screen time behavior. Final covariate selection for the multivariate models was performed through

145 backwards deletion using a 10\% change-in-estimate threshold (Rothman and Greenland, 1998). If a

146 covariate significantly changed the regression coefficient of at least one non-traditional family structure 
147 in at least one of the models, it was included in all final models. All covariates of interest met this 148 criterion.

149 Approximately $15 \%$ of participants were missing data for at least one relevant exposure,

150 outcome, or confounding variable. Because we were concerned that this would bias our results, we

151 performed two forms of multiple imputation for the missing data, one based on fully conditional

152 specification and the other based on the use of Monte Carlo Markov Chains. Because the two

153 imputation methods produced consistent and similar results, only the results from the fully conditional

154 specification-based imputation are shown in the manuscript. This method is more appropriate for the

155 imputation of categorical data because it does not assume normality of imputed variables (Lee and

156 Carlin, 2010). In both imputation procedures, all variables were included for the multiple imputation,

157 and 50 concatenated datasets were created rather than the typical 5 in an effort to reduce any potential

158 bias caused by rounding.

\section{RESULTS}

160 Sample characteristics

161 Demographic characteristics of the sample are in Table 1. The majority of participants had lived

162 in Canada for more than 5 years (94.4\%), were of Canadian (Caucasian or Aboriginal) ethnicity

$163(75.3 \%)$, and considered themselves to be of higher than average socioeconomic status (53.7\%). Most

164 participants lived in traditional, dual-parent families (65.0\%), followed by single parent families with

165 irregular visitation with their non-custodial parent (13.4\%), reconstituted families with irregular

166 visitation (6.6\%), single parent families with regular visitation (4.2\%) and finally reconstituted families

167 with regular visitation (2.7\%). Most participants exceeded Canada's recreational screen time

168 guidelines, with $80.6 \%$ reporting that they spent a cumulative total of more than 2 hours per day

169 watching television, playing video games, and using a computer. The average weekly screen time was

$170 \quad 59.4$ hours in boys and 53.4 hours in girls. 


\section{Relationships between family structure and screen time}

As shown in Table 2, youth from non-traditional families had slightly higher screen time values

173 than youth from traditional families, although few differences were statistically significant and even the

174 significant differences were small in magnitude (e.g., $<5$ hours/week difference between the mean

175 screen time in the non-traditional and traditional).

176 Tables 3 to 6 show odds ratios for being in the highest quartile of weekly screen time by family

177 structure, with traditional families serving as the referent group. Statistically significant $(\mathrm{p}<0.05$, after

178 Bonferroni correction) relationships are shown in bold. There were several significant relationships in

179 the bivariate analyses. However, these significant relationships were weak in strength (i.e., odds ratios

$180<1.25)$ and were not consistent across gender or the three screen time behaviors. Furthermore, these

181 relationships were no longer significant after controlling for the confounding variables.

183 when the definition of elevated screen time was changed from being in the highest quartile of screen

184 usage to exceeding a 2 hour/day threshold (data not shown). The associations also did not change

185 based on the choice of imputation methods (data not shown). The relationships observed in the imputed data were, however, different from those estimated using a full case analysis in which observations with missing data were simply deleted. For example, the odds ratios for boys from single

188 parent families being in the highest quartile of video game usage were significant in the full case

189 analysis (OR 1.40, 95\% CI: $1.22-1.60$ for those with irregular visitation and OR 1.48, 95\% CI: $1.05-$

1902.09 for those with regular visitation), indicating that boys from single parent families watched more

191 television than those from traditional families regardless of visitation. However, these odds ratios were

192 not significant when using the imputation models to reduce biases resulting from missing data (OR

193 1.13, 95\% CI: 0.96-1.34 and OR 1.17, 95\% CI: 0.91-1.51, respectively). 
194

195

196

197

198

199

200

201

202

203

204

205

206

207

208

209

210

211

212

213

214

215

216

\section{DISCUSSION}

The goal of this study was to examine non-traditional family structures — specifically single parent or reconstituted families, as well as shared custody arrangements — as potential predictors of excessive screen time in youth. While youth from non-traditional families did spend slightly more hours per week in total screen time, these differences were subtle $(<15 \%)$ and generally not statistically significant. Youth from non-traditional families were also not significantly more likely to exceed screen time guidelines or be in the highest quartile of weekly television, video game, or computer use after controlling for relevant covariates.

Our findings were consistent with previous quantitative studies of television viewing in youth, which have generally shown null results or subtle or insignificant increases in television-viewing in youth from single parent families (Lindquist et al., 1999; Salmon et al., 2005; Bagley et al., 2006; Hesketh et al., 2006; Gorely et al., 2009) and youth from reconstituted families (Quarmby et al., 2011; Sisson and Broyles, 2012). Only one previous study has looked at the influence of family structure on screen behaviors other than television (Gorely et al., 2009). While we did observe descriptive differences in the amount of time spent playing video games and using a computer by gender, we did not observe any meaningful interactions between gender and family structure.

To our knowledge, this study was the first to consider visitation with the non-residential parent as a potential predictor of differences in screen time behavior. It has been suggested that youth who regularly travel to visit another parent may have less time to do anything but sedentary activities (Quarmby and Dagkas, 2010). Our research did not support this argument, showing no consistent significant differences in screen time based on visitation with the non-custodial parent. This is consistent with evidence demonstrating that screen time is associated with mental and emotional health (Tremblay et al., 2011b), and additional findings that children in the shared physical custody of their 
217 separated parents experience similar emotional well-being to those who live in a traditional family

218 (Bauserman, 2002; Jablonska and Lindberg, 2007; Bjarnason et al., 2012).

219 It has been hypothesized that time and energy constraints experienced by single parents may

220 create environments that encourage sedentary behavior in their children (Quarmby and Dagkas, 2010;

221 Quarmby et al., 2011). Our research does not support that argument. Screen time, and particularly time 222 spent watching television, was high in all family structure groups and not just among youth from single 223 parent homes. Therefore, while interventions to decrease screen time in youth are necessary, these 224 interventions likely do not need to target youth in non-traditional family structures as a high risk group. structures in our analyses. Furthermore, the findings are generalizable as they are based on a nationally representative sample. Another strength was the use of multiple imputation to handle missing data in partially completed surveys, which is a common concern when analyzing survey data (Lee and Carlin, 2010). In our study $\sim 15 \%$ of observations had data missing for at least one variable. Multiple imputation avoids the assumption that the associations observed between screen time and family

231 structure are the same among those who answered all questions and those who did not. The fact that the 232 results from the imputed analyses were somewhat different from those based on full cases suggests that 233 we would have biased some of the effect estimates had we not used imputation. This has implications 234 for future studies with HBSC and other youth survey data. Our study also had important weaknesses. Several potential covariates and mediators were not 236 available in the dataset, such as family co-participation in screen time behaviors, parental employment 237 status, parental modeling, and house rules related to screen time. We were also unable to determine 238 how long participants had been in their current family structure. All of the variables used were based 239 on self-report, and were therefore subject to recall and/or social desirability bias. Finally, selection bias 
240 was a concern given that youth who did not provide consent or who were absent from school on the 241 day of the survey may have been systematically different from those who did participate.

In conclusion, family structure was not a meaningful predictor of screen time in this large and

243 representative sample of Canadian youth. Future research should focus on identifying further

244 determinants of sedentary behavior, and the mechanisms through which family structure influences

245 other health behaviors and outcomes.

247 REFERENCES

248 American Academy of Pediatrics. 2001. Children, adolescents, and television. Pediatrics 107:423-426.

249 Bagley S, Salmon J, Crawford D. 2006. Family structure and children's television viewing and physical activity. Med Sci Sports Exerc 38:910-918.

251

252

Bauserman R. 2002. Child adjustment in joint-custody versus sole-custody arrangements: a meta-analytic review. J Fam Psychol 16:91-102.

Bjarnason T, Bendtsen P, Borup I. 2012. Life satisfaction among children in different family structures: A comparative study of 36 western countries. Children \& Society 26:51-62.

Bramlett MD, Blumberg SJ. 2007. Family structure and children's physical and mental health. Health Aff (Millwood) 26:549-558.

Currie C, Nic Gabhainn S, Godeau E. 2009. The Health Behaviour in School-aged Children: WHO Collaborative Cross-National (HBSC) study: origins, concept, history and development 1982-2008. Int J Public Health 54 Suppl 2:131-139.

Freeman JG, King M, Pickett W, editors. 2012. The Health of Canada's Young People: A Mental Health Focus. Ottawa, ON: Public Health Agency of Canada.

Gorely T, Atkin AJ, Biddle SJ, Marshall SJ. 2009. Family circumstance, sedentary behaviour and physical activity in adolescents living in England: Project STIL. Int J Behav Nutr Phys Act 6:33. 
264 265

Gorley T, Marshall SJ, Biddle SJ. 2004. Couch kids: Correlates of television viewing among youth. Int J Behav Med 11:152-163.

\section{Hardy LL, Baur LA, Garnett SP, Crawford D, Campbell KJ, Shrewsbury VA, Cowell CT, Salmon J.} 2006. Family and home correlates of television viewing in 12-13 year old adolescents: the Nepean Study. Int J Behav Nutr Phys Act 3:24.

Hesketh K, Crawford D, Salmon J. 2006. Children's television viewing and objectively measured physical activity: associations with family circumstance. Int J Behav Nutr Phys Act 3:36.

Jablonska B, Lindberg L. 2007. Risk behaviours, victimisation and mental distress among adolescents in different family structures. Soc Psychiatry Psychiatr Epidemiol 42:656-663.

Lee KJ, Carlin JB. 2010. Multiple imputation for missing data: fully conditional specification versus multivariate normal imputation. Am J Epidemiol 171:624-632.

Lindquist CH, Reynolds KD, Goran MI. 1999. Sociocultural determinants of physical activity among children. Prev Med 29:305-312.

Quarmby T, Dagkas S. 2010. Chlidren's engagement in leisure time physical activity: Exploring family structure as a determinant. Leisure Studies 29:53-66.

Quarmby T, Dagkas S, Bridge M. 2011. Associations between children's physical activities, sedentary behaviours and family structure: a sequential mixed methods approach. Health Educ Res 26:63-76.

Rothman KJ, Greenland S. 1998. Modern Epidemiology. New York, NY: Lippincott, Williams and Wilkins.

Salmon J, Timperio A, Telford A, Carver A, Crawford D. 2005. Association of family environment with children's television viewing and with low level of physical activity. Obes Res 13:1939-1951.

Schmitz KH, Harnack L, Fulton JE, Jacobs DR, Jr., Gao S, Lytle LA, Van Coevering P. 2004. Reliability and validity of a brief questionnaire to assess television viewing and computer use by middle school children. $J$ Sch Health 74:370-377.

Sisson SB, Broyles ST. 2012. Social-ecological correlates of excessive TV viewing: difference by race and sex. J Phys Act Health 9:449-455. 
289 Thomson E, McLanahan SS. 2012. Reflections on "family sctructure and child well-being: Economic resources vs. parental socialization". Soc Forces 91:45-53.

291 Tremblay MS, Leblanc AG, Janssen I, Kho ME, Hicks A, Murumets K, Colley RC, Duggan M. 2011 a.

292 Canadian sedentary behaviour guidelines for children and youth. Appl Physiol Nutr Metab 36:59-64; 65-

29371.

294 Tremblay MS, LeBlanc AG, Kho ME, Saunders TJ, Larouche R, Colley RC, Goldfield G, Gorber SC.

295 2011b. Systematic review of sedentary behaviour and health indicators in school-aged children and 296 youth. Int J Behav Nutr Phys Act 8:98.

297

298 
Table $\mathbf{1}$ (on next page)

Characteristics of the 2009/10 Canadian Health Behaviour in School-aged Children survey

$\mathrm{N}=$ Number of sampled individuals with complete valid data for all variables presented.

*Estimated population characteristics after adjusting for sampling weights and clustering. 
2 Table 1. Characteristics of the 2009/10 Canadian Health Behaviour in School-aged Children survey

\begin{tabular}{|c|c|c|}
\hline Characteristic & $\mathbf{N}$ & $\%(95 \% \text { CI })^{*}$ \\
\hline \multicolumn{3}{|l|}{ Gender } \\
\hline Male & 12878 & $49.1(47.7-50.6)$ \\
\hline Female & 13169 & $50.8(49.4-52.3)$ \\
\hline Missing & 31 & $0.0(0.0-0.1)$ \\
\hline \multicolumn{3}{|l|}{ Grade } \\
\hline Grade 5 & 55 & $0.25(0.00-0.51)$ \\
\hline Grade 6 & 5110 & $19.6(16.1-23.0)$ \\
\hline Grade 7 & 5205 & $20.0(17.6-22.3)$ \\
\hline Grade 8 & 5266 & $20.2(17.7-22.7)$ \\
\hline Grade 9 & 5395 & $20.7(17.4-23.9)$ \\
\hline Grade 10 & 4871 & $18.8(15.5-22.1)$ \\
\hline Grade 11 & 176 & $0.55(0.37-0.73)$ \\
\hline Missing & 0 & 0 \\
\hline \multicolumn{3}{|l|}{ Self-Perceived Family Wealth } \\
\hline Low & 2411 & $9.0(8.4-9.6)$ \\
\hline Average & 8581 & $31.7(30.4-33.0)$ \\
\hline High & 13466 & $53.7(52.1-55.2)$ \\
\hline Missing & 1620 & $5.6(4.6-6.6)$ \\
\hline \multicolumn{3}{|l|}{ Immigrant Status } \\
\hline Lived in Canada $\geq 5$ years & 24709 & $94.4(93.4-95.3)$ \\
\hline Lived in Canada $<5$ years & 1093 & $4.6(3.8-5.5)$ \\
\hline Missing & 276 & $1.0(0.80-1.2)$ \\
\hline \multicolumn{3}{|l|}{ Parental Structure } \\
\hline Traditional family & 16504 & $65.0(63.6-66.5)$ \\
\hline Single parent with regular visitation & 997 & $4.2(3.8-4.6)$ \\
\hline Single parent with irregular visitation & 3594 & $13.4(12.6-14.2)$ \\
\hline Reconstituted with regular visitation & 662 & $2.7(2.4-3.0)$ \\
\hline Reconstituted with irregular visitation & 1744 & $6.6(6.0-7.1)$ \\
\hline Other & 1533 & $5.0(4.5-5.5)$ \\
\hline Missing & 1044 & $3.0(2.6-3.5)$ \\
\hline \multicolumn{3}{|l|}{ Siblings } \\
\hline Only Child & 3787 & $13.5(12.7-14.3)$ \\
\hline$\geq 1$ sibling & 21253 & $83.2(82.4-84.1)$ \\
\hline Missing & 1038 & $3.3(2.8-3.7)$ \\
\hline Ethnicity & & \\
\hline
\end{tabular}




\begin{tabular}{|c|c|c|}
\hline Canadian & 20624 & $75.3(71.8-78.7)$ \\
\hline East and Southeast Asian & 1285 & $5.7(4.0-7.3)$ \\
\hline South Asian & 656 & $3.2(2.2-4.2)$ \\
\hline Black & 481 & $2.6(1.9-3.3)$ \\
\hline Arab & 229 & $1.3(0.7-1.8)$ \\
\hline Latin American & 191 & $0.9(0.6-1.2)$ \\
\hline Other & 2294 & $10.0(9.0-11.0)$ \\
\hline Missing & 318 & $1.1(0.9-1.3)$ \\
\hline \multicolumn{3}{|l|}{ Television Viewing } \\
\hline$\leq 2 \mathrm{hrs} /$ day & 12508 & $50.5(49.0-51.9)$ \\
\hline$>2 \mathrm{hrs} / \mathrm{day}$ & 11128 & $41.5(40.0-43.1)$ \\
\hline Missing & 2442 & $8.0(7.1-8.9)$ \\
\hline \multicolumn{3}{|l|}{ Video Game Use } \\
\hline$\leq 2 \mathrm{hrs} / \mathrm{day}$ & 15512 & $32.1(30.9-33.2)$ \\
\hline$>2 \mathrm{hrs} /$ day & 8170 & $60.2(58.7-61.8)$ \\
\hline Missing & 2396 & $7.7(6.8-8.6)$ \\
\hline \multicolumn{3}{|l|}{ Computer Use } \\
\hline$\leq 2 \mathrm{hrs} /$ day & 8902 & $36.8(35.3-38.3)$ \\
\hline$>2 \mathrm{hrs} /$ day & 14819 & $55.5(53.8-57.2)$ \\
\hline Missing & 2357 & $7.7(6.8-8.5)$ \\
\hline \multicolumn{3}{|l|}{ Total Screen Time } \\
\hline$\leq 2 \mathrm{hrs} /$ day & 2706 & $9.7(8.8-10.5)$ \\
\hline$>2 \mathrm{hrs} /$ day & 20510 & $80.6(79.6-81.7)$ \\
\hline Missing & 2862 & $9.7(8.7-10.6)$ \\
\hline
\end{tabular}

$3 \overline{\mathrm{N}}=$ Number of sampled individuals with complete valid data for all variables presented.

4 *Estimated population characteristics after adjusting for sampling weights and clustering. 
Table 2 (on next page)

Mean weekly hours of screen time (television, video games and computer) according to family structure

Data presented as mean ( $95 \%$ confidence interval) after adjusting for sample weights and clustering and the following covariates: grade, immigration, siblings, ethnicity, and family wealth.

* Significantly different from traditional families after taking into account multiple comparisons (Bonferroni-adjusted p-value $<0.05$ ) 
2 Table 2. Mean weekly hours of screen time (television, video games and computer) according to family structure

\begin{tabular}{|c|c|c|c|c|c|}
\hline Family Structure Group & $\mathbf{N}$ & Mean $(95 \%$ CI) & Computer & Video Games & $\begin{array}{c}\text { Total Screen } \\
\text { Time } \\
\text { Mean }(95 \% \mathrm{CI})\end{array}$ \\
\hline \multicolumn{6}{|l|}{ Boys } \\
\hline Traditional & 8699 & $20.2(19.1-21.3)$ & $15.1(14.1-16.2)$ & $16.8(15.8-17.8)$ & $52.1(49.4-54.9)$ \\
\hline Reconstituted with irregular visitation & 784 & $21.7(19.9-23.4)$ & $16.9(15.1-18.6)$ & $18.6(16.9-20.3)$ & $57.1(53.1-61.2)$ \\
\hline Reconstituted with regular visitation & 295 & $19.0(16.5-21.5)$ & $15.3(13.0-17.6)$ & $18.7(16.3-21.1)$ & $53.0(47.6-58.4)$ \\
\hline Single parent with irregular visitation & 1763 & $20.8(19.4-22.1)$ & $16.5(15.2-17.8)$ & $19.5(18.2-20.7) *$ & $56.8(53.6-59.9) *$ \\
\hline Single parent with regular visitation & 494 & $21.8(19.6-23.9)$ & $17.2(15.1-19.4)$ & $20.3(18.2-22.3) *$ & $59.3(54.0-64.6) *$ \\
\hline \multicolumn{6}{|l|}{ Girls } \\
\hline Traditional & 8774 & $19.0(17.9-20.0)$ & $17.6(16.6-18.6)$ & $9.7(8.8-10.7)$ & $46.3(43.8-48.7)$ \\
\hline Reconstituted with irregular visitation & 988 & $20.1(18.4-21.7)$ & $18.4(16.9-19.9)$ & $10.4(8.9-11.8)$ & $48.8(45.2-52.3)$ \\
\hline Reconstituted with regular visitation & 414 & $20.3(18.2-22.4)$ & $20.4(18.2-22.6) *$ & $11.2(9.2-13.2)$ & $51.9(46.6-57.1)$ \\
\hline Single parent with irregular visitation & 1860 & $20.7(19.5-21.9) *$ & $19.4(18.3-20.5) *$ & $11.0(9.8-12.2)$ & $51.1(48.2-53.9) *$ \\
\hline Single parent with regular visitation & 581 & $19.5(17.8-21.3)$ & $19.2(17.2-21.2)$ & $11.2(9.3-13.0)$ & $49.9(45.5-54.2)$ \\
\hline
\end{tabular}

Data presented as mean (95\% confidence interval) after adjusting for sample weights and clustering and the following covariates: grade, immigration,

4 siblings, ethnicity, and family wealth.

$5 *$ Significantly different from traditional families after taking into account multiple comparisons (Bonferroni-adjusted $p$-value $<0.05$ ) 


\section{Table 3(on next page)}

Relationships between family structure and being in the highest television viewing quartile

Note: All analyses account for sample weights and clustering. Statistically significant odds ratios are shown in bold.

*Adjusted for the following covariates: grade, immigration, siblings, ethnicity, and family wealth. 
2 Table 3. Relationships between family structure and being in the highest television viewing quartile

\begin{tabular}{|c|c|c|c|}
\hline Family Structure Group & $\begin{array}{l}\text { Frequency, } \\
\%(95 \% \mathrm{CI})\end{array}$ & $\begin{array}{c}\text { Bivariate Analysis, } \\
\text { OR }(95 \% \text { CI })\end{array}$ & $\begin{array}{c}\text { Fully Adjusted Model,* } \\
\text { OR (95\% CI) }\end{array}$ \\
\hline \multicolumn{4}{|l|}{ Boys } \\
\hline Traditional & $27.5(25.5-29.5)$ & 1.00 & 1.00 \\
\hline Reconstituted with irregular visitation & $32.9(27.8-38.0)$ & $1.21(0.99-1.49)$ & $1.20(0.98-1.49)$ \\
\hline Reconstituted with regular visitation & $20.6(13.9-27.3)$ & $0.64(0.46-0.89)$ & $0.66(0.47-0.92)$ \\
\hline Single parent with irregular visitation & $31.9(28.4-35.5)$ & $1.16(0.99-1.36)$ & $1.11(0.94-1.31)$ \\
\hline Single parent with regular visitation & $32.3(25.7-38.9)$ & $1.18(0.91-1.53)$ & $1.19(0.91-1.55)$ \\
\hline \multicolumn{4}{|l|}{ Girls } \\
\hline Traditional & $24.6(22.8-26.4)$ & 1.00 & 1.00 \\
\hline Reconstituted with irregular visitation & $28.4(24.1-32.6)$ & $1.05(0.88-1.26)$ & $1.05(0.88-1.26)$ \\
\hline Reconstituted with regular visitation & $28.6(21.9-35.4)$ & $1.07(0.82-1.40)$ & $1.12(0.86-1.47)$ \\
\hline Single parent with irregular visitation & $31.3(28.4-34.2)$ & $1.21(1.05-1.40)$ & $1.14(0.98-1.32)$ \\
\hline Single parent with regular visitation & $24.0(18.9-29.1)$ & $0.84(0.66-1.07)$ & $0.84(0.66-1.06)$ \\
\hline
\end{tabular}

3 Note: All analyses account for sample weights and clustering. Statistically significant odds ratios are shown in bold.

4 * Adjusted for the following covariates: grade, immigration, siblings, ethnicity, and family wealth. 


\section{Table 4(on next page)}

Relationships between family structure and being in the highest computer use quartile Note: All analyses account for sample weights and clustering. Statistically significant odds ratios are shown in bold.

*Adjusted for the following covariates: grade, immigration, siblings, ethnicity, and family wealth. 
2 Table 4. Relationships between family structure and being in the highest computer use quartile

\begin{tabular}{|c|c|c|c|}
\hline Family Structure Group & $\begin{array}{l}\text { Frequency, } \\
\%(95 \% \mathrm{CI})\end{array}$ & $\begin{array}{c}\text { Bivariate Analysis, } \\
\text { OR }(95 \% \text { CI })\end{array}$ & $\begin{array}{c}\text { Fully Adjusted Model,* } \\
\text { OR (95\% CI) }\end{array}$ \\
\hline \multicolumn{4}{|l|}{ Boys } \\
\hline Traditional & $20.3(18.6-22.1)$ & 1.00 & 1.00 \\
\hline Reconstituted with irregular visitation & $26.4(21.3-31.6)$ & $1.12(0.90-1.39)$ & $1.07(0.86-1.35)$ \\
\hline Reconstituted with regular visitation & $22.9(15.6-30.2)$ & $0.92(0.66-1.29)$ & $0.95(0.68-1.33)$ \\
\hline Single parent with irregular visitation & $27.3(24.1-30.5)$ & $1.17(0.98-1.38)$ & $1.08(0.91-1.29)$ \\
\hline Single parent with regular visitation & $25.2(18.9-31.6)$ & $1.05(0.79-1.38)$ & $1.14(0.86-1.50)$ \\
\hline \multicolumn{4}{|l|}{ Girls } \\
\hline Traditional & $27.5(25.6-29.5)$ & 1.00 & 1.00 \\
\hline Reconstituted with irregular visitation & $33.4(29.3-37.6)$ & $1.08(0.92-1.28)$ & $1.02(0.86-1.21)$ \\
\hline Reconstituted with regular visitation & $33.0(26.6-39.5)$ & $1.06(0.85-1.34)$ & $1.14(0.90-1.45)$ \\
\hline Single parent with irregular visitation & $35.1(31.5-38.8)$ & $1.17(1.02-1.34)$ & $1.10(0.95-1.26)$ \\
\hline Single parent with regular visitation & $29.6(23.3-35.9)$ & $0.91(0.72-1.15)$ & $0.93(0.73-1.18)$ \\
\hline
\end{tabular}

3 Note: All analyses account for sample weights and clustering. Statistically significant odds ratios are shown in bold.

4 * Adjusted for the following covariates: grade, immigration, siblings, ethnicity, and family wealth. 
Table 5(on next page)

Relationships between family structure and being in the highest video game use quartile

Note: All analyses account for sample weights and clustering. Statistically significant odds ratios are shown in bold.

${ }^{*}$ Adjusted for the following covariates: grade, immigration, siblings, ethnicity, and family wealth. $v$ 
2 Table 5. Relationships between family structure and being in the highest video game use quartile

\begin{tabular}{|c|c|c|c|}
\hline Family Structure Group & $\begin{array}{l}\text { Frequency, } \\
\%(95 \% \mathrm{CI})\end{array}$ & $\begin{array}{c}\text { Bivariate Analysis, } \\
\text { OR }(95 \% \text { CI })\end{array}$ & $\begin{array}{c}\text { Fully Adjusted Model,* } \\
\text { OR (95\% CI) }\end{array}$ \\
\hline \multicolumn{4}{|l|}{ Boys } \\
\hline Traditional & $33.1(31.4-34.9)$ & 1.00 & 1.00 \\
\hline Reconstituted with irregular visitation & $39.1(33.8-44.5)$ & $1.00(0.82-1.21)$ & $0.97(0.80-1.18)$ \\
\hline Reconstituted with regular visitation & $38.2(30.1-46.3)$ & $0.96(0.73-1.26)$ & $0.97(0.74-1.28)$ \\
\hline Single parent with irregular visitation & $42.4(39.1-45.6)$ & $1.14(0.97-1.34)$ & $1.11(0.94-1.31)$ \\
\hline Single parent with regular visitation & $43.4(35.6-51.1)$ & $1.19(0.93-1.53)$ & $1.18(0.92-1.52)$ \\
\hline \multicolumn{4}{|l|}{ Girls } \\
\hline Traditional & $15.1(13.8-16.4)$ & 1.00 & 1.00 \\
\hline Reconstituted with irregular visitation & $16.6(13.3-20.0)$ & $0.95(0.77-1.16)$ & $0.92(0.75-1.13)$ \\
\hline Reconstituted with regular visitation & $18.3(13.2-23.4)$ & $1.07(0.80-1.41)$ & $1.12(0.84-1.49)$ \\
\hline Single parent with irregular visitation & $19.1(16.2-22.0)$ & $1.12(0.94-1.34)$ & $1.05(0.88-1.26)$ \\
\hline Single parent with regular visitation & $17.9(12.7-23.2)$ & $1.04(0.79-1.37)$ & $1.06(0.80-1.39)$ \\
\hline
\end{tabular}

3 Note: All analyses account for sample weights and clustering. Statistically significant odds ratios are shown in bold.

$4{ }^{*}$ Adjusted for the following covariates: grade, immigration, siblings, ethnicity, and family wealth. 
Table 6 (on next page)

Relationships between family structure and being in the highest total screen time quartile

Note: All analyses account for sample weights and clustering. Statistically significant odds ratios are shown in bold.

*Adjusted for the following covariates: grade, immigration, siblings, ethnicity, and family wealth. 
2 Table 6. Relationships between family structure and being in the highest total screen time quartile

\begin{tabular}{|c|c|c|c|}
\hline Family Structure Group & $\begin{array}{l}\text { Frequency, } \\
\%(95 \% \mathrm{CI})\end{array}$ & $\begin{array}{c}\text { Bivariate Analysis, } \\
\text { OR }(95 \% \text { CI })\end{array}$ & $\begin{array}{c}\text { Fully Adjusted Model,* } \\
\text { OR (95\% CI) }\end{array}$ \\
\hline \multicolumn{4}{|l|}{ Boys } \\
\hline Traditional & $28.4(26.3-30.6)$ & 1.00 & 1.00 \\
\hline Reconstituted with irregular visitation & $34.8(29.6-40.0)$ & $1.07(0.88-1.30)$ & $1.05(0.86-1.28)$ \\
\hline Reconstituted with regular visitation & $29.2(21.8-36.7)$ & $0.83(0.62-1.12)$ & $0.85(0.63-1.15)$ \\
\hline Single parent with irregular visitation & $37.8(34.2-41.3)$ & $1.22(1.04-1.44)$ & $1.15(0.98-1.36)$ \\
\hline Single parent with regular visitation & $36.4(29.3-43.5)$ & $1.15(0.90-1.47)$ & $1.19(0.92-1.52)$ \\
\hline \multicolumn{4}{|l|}{ Girls } \\
\hline Traditional & $21.6(19.8-23.4)$ & 1.00 & 1.00 \\
\hline Reconstituted with irregular visitation & $24.0(19.8-28.1)$ & $0.96(0.81-1.15)$ & $0.93(0.78-1.11)$ \\
\hline Reconstituted with regular visitation & $26.7(20.5-32.9)$ & $1.11(0.86-1.43)$ & $1.19(0.91-1.54)$ \\
\hline Single parent with irregular visitation & $27.7(24.6-30.8)$ & $1.17(1.00-1.36)$ & $1.08(0.93-1.27)$ \\
\hline Single parent with regular visitation & $23.7(18.2-29.3)$ & $0.95(0.74-1.22)$ & $0.96(0.75-1.23)$ \\
\hline
\end{tabular}

3 Note: All analyses account for sample weights and clustering. Statistically significant odds ratios are shown in bold.

4 * Adjusted for the following covariates: grade, immigration, siblings, ethnicity, and family wealth. 